\title{
Anhysteretic Magnetization for NiFeMo Soft Magnetic Compacted Powder
}

\author{
D. OlekšÁKOvá ${ }^{a, *}$, P. KOlláR ${ }^{b}$, M. JakubČin ${ }^{b}$, P. SlovenskÝ ${ }^{b}$, \\ Z. BirČÁKOVÁ ${ }^{c}$, J. FÜZER ${ }^{b}$, M. FÁBEROVÁ ${ }^{c}$ AND R. BureS̆ ${ }^{c}$ \\ ${ }^{a}$ Institute of Manufacturing Management, Faculty of Manufacturing Technologies with the seat in Prešov, \\ Technical University of Košice, Bayerova 1, 08001 Prešov, Slovakia \\ ${ }^{b}$ Institute of Physics, Faculty of Science, P.J. Šafárik University, Park Angelinum 9, 04154 Košice, Slovakia \\ ${ }^{c}$ Institute of Materials Research, Slovak Academy of Sciences, Watsonova 47, 04353 Košice, Slovakia \\ Experimentally obtained anhysteretic curves, which characterize NiFeMo soft magnetic compacted powders \\ were measured by modified DC hysteresisgraph. Two anhysteretic curves of two properly prepared samples were \\ compared. First sample was compacted from powder obtained by milling of small chips with particle size between \\ $100 \mu \mathrm{m}$ and $300 \mu \mathrm{m}$. Then, the surface particles were mechanically smoothed. Second sample was prepared \\ in the same way as first one, only that after compaction the sample was annealed at $1100{ }^{\circ} \mathrm{C}$. Numerical analysis \\ of anhysteretic curves showed that the origin of the improvement of the soft magnetic properties of the bulk is \\ due to annealing.
}

DOI: 10.12693/APhysPolA.137.889

PACS/topics: soft magnetic material, anhysteretic curve, demagnetization factor

\section{Introduction}

Nickel iron alloys (permalloys) are important in many areas of science from material research and engineering [1] to the planetary sciences (founded in most meteorite classes) [2]. High permeability and low magnetostrictive properties of permalloys are widely used in magnetic cores for electrical equipment applications. They are also useful as magnetic shielding materials [3]. Nickel iron alloys are still attractive systems to study because their applications being one of the primary concerns in science and technology of materials $[4,5]$.

In the present work, we study Ni-rich Mo substituted permalloys. Generally, Mo enhances material permeability even if a small amount is added [6]. High permeability can be also achieved by reducing the amount of $\mathrm{Ni}$. In turn, Mo increases the electrical resistivity of permalloys, and reduces eddy current losses at the same time. Iron nickel molybdenum alloys (called supermalloy) show excellent high frequency characteristics $[6,7]$.

The appropriate structure of the supermalloy (produced usually in the form of thin sheet) with initial permeability much larger than that of pure iron arises after proper heat treatment. For some applications the form of a sheet is not suitable, therefore it is logical to try to prepare such material in another form, for example in a form of a ring. This shape would be more convenient for construction of some type components for electronic devices [6]. One of the methods of preparing 3D samples is the compaction of powder obtained by the mechanical milling, or mechanical alloying [8].

*corresponding author; e-mail: denisa.oleksakova@tuke.sk
In this paper, we demonstrate the matching to the anhysteretic curve of experimental data for compacted $\mathrm{Ni}_{80} \mathrm{Fe}_{15} \mathrm{Mo}_{5}$ (wt. \%) based on the Jiles-Atherton model with an additional parameter. The influence of annealing on parameters from the Jiles-Atherton model is also examined.

\section{Experimental}

Small chips $\mathrm{Ni}_{80} \mathrm{Fe}_{15} \mathrm{Mo}_{5}$ (wt. \%) with size of $2 \mathrm{~mm}$ were prepared from the sheet by a rotary drill grinder mounted in a lathe. The chips were milled in a planetary ball mill Retch PM100 in steel vial with steel balls for $10 \mathrm{~min}$ with BPR ratio 10:1. The morphology of the chips and the milled chips (powder) was scanned by optical microscope (Nikon Epiphot 200), and scanning electron microscope (TESCAN VEGA3), displayed in Fig. 1. The milled powder was sieved to obtain size fraction from $100 \mu \mathrm{m}$ to $300 \mu \mathrm{m}$. The powder particles were mechanically smoothed [9], and compacted by uniaxial pressure of $700 \mathrm{MPa}$ at the temperature of $410^{\circ} \mathrm{C}$ with durability of $10 \mathrm{~min}$, sample A. The B sample was prepared by the same way, only after compaction the sample was annealed at $1100^{\circ} \mathrm{C}$ for 10 hours in hydrogen atmosphere. The dimensions of resulted bulk samples were: height of $2.9 \mathrm{~mm}$, outer diameter of $24 \mathrm{~mm}$, and inner diameter of $18 \mathrm{~mm}$. The detailed samples parameters including density are given in [9].

\section{Anhysteretic curves}

The anhysteretic magnetization curve (also called "ideal magnetization" [10]) is a concept used extensively in the characterization of magnetic materials. Anhysteretic magnetization is defined as the "thermal equilibrium" curve measured by the cooling the sample from 


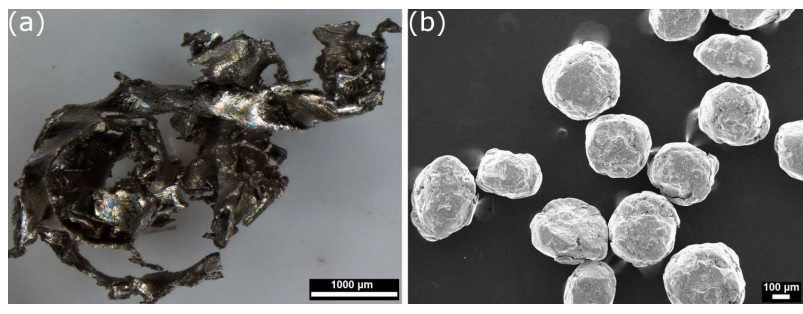

Fig. 1. The morphology (a) of the chips $\mathrm{Ni}_{80} \mathrm{Fe}_{15} \mathrm{Mo}_{5}$ (wt\%), visualized by optical microscope, and (b) the powdered chips, which powder element were mechanically smoothed $\mathrm{Ni}_{80} \mathrm{Fe}_{15} \mathrm{Mo}_{5}$ (wt\%) visualized by SEM.

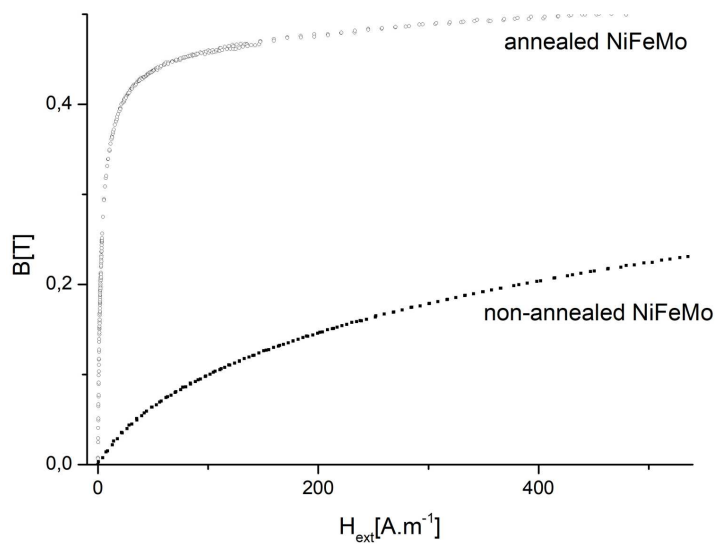

Fig. 2. Anhysteresis curves of compacted $\mathrm{Ni}_{80} \mathrm{Fe}_{15} \mathrm{Mo}_{5}$ (wt\%) before the annealing and after the annealing at $1100{ }^{\circ} \mathrm{C}$.

the Curie temperature in an incrementally increased direct current DC field [11, 12]. The most important utilization of anhysteretic curves is in magnetic recording, where the superposition of high frequency field (also called "bias") on the signal is used to overcome the hysteresis of the recording medium [12].

Anhysteretic curves (Fig. 2) were measured by modified DC hysteresisgraph. The AC field with decreased amplitude was applied at every measured point along the magnetization curve by the third toroidal winding to obtain experimental points of anhysteretic curve [13, 14]. In the figure there are the values of external magnetic field $H_{\text {ext }}$ (produced by third windings on ring-shaped sample) on x-axis.

\section{Inner demagnetization factor}

Since the samples used for measurements were prepared by compaction of powder, then each powder element as a source of demagnetizing field reduces the value of internal magnetic field $H_{\mathrm{int}}$. It is expressed as follows:

$$
H_{\text {int }}=H_{\text {ext }}-H_{d}=H_{\text {ext }}-N_{d} M,
$$

where $H_{\mathrm{d}}$ is demagnetization field, $N_{d}$ is inner demagnetization factor, and $M$ is the magnetization.

\section{TABLE I}

Calculated (dimensionless) coefficients of compacted $\mathrm{Ni}_{80} \mathrm{Fe}_{15} \mathrm{Mo}_{5}$ (wt \%) before the annealing and after the annealing at $1100^{\circ} \mathrm{C}$.

\begin{tabular}{l|c|c}
\hline \hline Coefficient & Before the annealing & After the annealing \\
\hline$N_{d}[-]$ & $6.69 \times 10^{-4}$ & $3.14 \times 10^{-6}$ \\
$K_{1}[\mathrm{~m} / \mathrm{A}]$ & $94 \times 10^{-4}$ & $10.385 \times 10^{-4}$ \\
$K_{2}[\mathrm{~m} / \mathrm{A}]$ & $5.07 \times 10^{-6}$ & $6.295 \times 10^{-6}$ \\
$m[\mathrm{~A} / \mathrm{m}]$ & $3049.36 \times 10^{-10}$ & $336.89 \times 10^{-10}$ \\
$\alpha[-]$ & $53.94 \times 10^{-3}$ & $6.06 \times 10^{-3}$
\end{tabular}

The demagnetization factor was determinated by the linear part of anhysteretic curve for $H_{\text {ext }} \rightarrow 0$. Demagnetization field in the sample depends on numerous parameters, such as shape and size of particles, and porosity [13]. To determine the demagnetization factor one can use formula [13]

$$
N_{d}=\left(\frac{B}{\mu_{0} H_{\mathrm{ext}}}-1\right)^{-1},
$$

where $B$ is the magnetic induction, and $B / H_{\text {ext }}$ is the slope of the linear part of anhysteretic curve. The values of demagnetization factor of compacted $\mathrm{Ni}_{80} \mathrm{Fe}_{15} \mathrm{Mo}_{5}$ (wt\%), before the annealing and after the annealing at $1100{ }^{\circ} \mathrm{C}$, are in Table I. The value of the demagnetization factor for annealed sample is significantly lower than that for non-annealed sample due to the paths creation between powder elements for magnetic induction.

\section{Jiles-Atherton model}

Nowadays, the anhysteretic magnetization curves are often processed with the Jiles-Atherton model of magnetic hysteresis [15]. This one of most popular magnetic models is suitable for design and simulations of electrotechnical and electronic components with soft magnetic cores [16]. The model itself is based on the anhysteretic curves, which are derived using a mean field approach, and where the magnetization of any domain is coupled to the magnetic field $H_{\text {int }}$ and the bulk magnetization $M[15,17]$.

According to Jiles-Atherton model [15] the energy $E$ of a domain with the magnetic moment $m$ of feromagnetic material in the presence of the magnetic field $H_{\text {int }}$ is:

$$
E=\mu_{0} m H_{E}=\mu_{0} m\left(H_{I}+H_{\text {int }}\right),
$$

where $\mu_{0}$ is permeability of vacuum, $H_{E}$ is the effective magnetic field, and $H_{I}$ is the magnetic field representing inter domain coupling. Typically, $H_{I}$ determines the shape of the anhysteretic magnetic curve, and according to the Jiles-Atherton model [15] it is

$$
H_{I}=f(M), \quad H_{I}(M)=\alpha M, \quad \alpha=\alpha(M),
$$

where $\alpha$ is a constant mean field parameter. Now, (3) can be rewritten as

$$
E=\mu_{0} m\left(\alpha M+H_{\text {int }}\right) .
$$



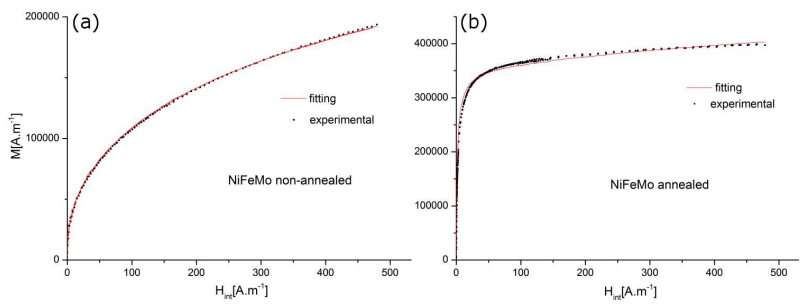

Fig. 3. Anhysteresis curves and calculated ones for fitted parameters $m, \alpha$ in Langevin function of $\mathrm{Ni}_{80} \mathrm{Fe}_{15} \mathrm{Mo}_{5}$ compacts before the annealing (a) and after the annealing (b) at $1100{ }^{\circ} \mathrm{C}$.

According to the Jiles-Atherton model, which is based on the idea of anhysteretic magnetization $M$ of ferromagnetic material, after applying Maxwell-Boltzman statistics (distribution of magnetization vectors of domains) and introducing the modified Langevin function $\mathcal{L}$, we can write:

$$
\begin{aligned}
& M=M_{s} \mathcal{L}\left(\frac{E}{k_{\mathrm{B}} T}\right)=M_{s} \mathcal{L}\left(\frac{\mu_{0} m}{k_{\mathrm{B}} T}\left(\alpha M+H_{\mathrm{int}}\right)\right) \\
& K_{1}=\frac{\mu_{0} m}{k_{\mathrm{B}} T}, \quad K_{2}=K_{1} \alpha, \\
& M=M_{s}\left(K_{1} H_{\mathrm{int}}+K_{2} M\right),
\end{aligned}
$$

where $k_{\mathrm{B}}$ is Boltzmann constant, $M_{s}$ is the saturation magnetization, and $K_{1}, K_{2}$ are parameters, which can be fitted according to ( 7 ) based on experimental data of anhysteretic curves for two compacted $\mathrm{Ni}_{80} \mathrm{Fe}_{15} \mathrm{Mo}_{5}$ samples (wt\%) before the annealing and after the annealing at $1100{ }^{\circ} \mathrm{C}$. Parameter $K_{1}$ depends on the room temperature $T$, and the average magnetic moment of an effective domain $m$. Definition of $K_{1}$ includes the Boltzman constant $k_{\mathrm{B}}$, as well as the magnetic constant $\mu_{0}$. Parameter $K_{2}$ is consistent with a constant mean field parameter $\alpha$ in (4).

The fitted parameters $K_{1}, K_{2}$, and calculated parameters $m, \alpha$ can be find in Table I. The values of $m$ are unexpectedly low, which is explained in [18]. The comparison between measured anhysteretic curves for both samples with theoretical ones obtained with $m$ and $\alpha$ parameters, is depicted in Fig. 3.

\section{Conclusions}

Experimental data of anhysteretic curves (before the annealing and after the annealing at $1100^{\circ} \mathrm{C}$ ) of the compacted powder $\mathrm{Ni}_{80} \mathrm{Fe}_{15} \mathrm{Mo}_{5}$ sample with particle size from $100 \mu \mathrm{m}$ to $300 \mu \mathrm{m}$, were compared with Jiles-Atherton model for ferromagnetic material. At first, however, the parameters of Langevin function were determined. The annealing causes a significant decrease of the parameter $m$ (the average magnetic moment of an effective domain), and a slight decrease of the parameter $\alpha$ (the mean field parameter). It is treated as a consequence of the creation of the paths for magnetic flux between powder elements in the compacted material.
The decrease of parameters values leads to stronger coupling, and denser effective domains after annealing. We can summarize that the presented model matches the experimental data with very good accuracy.

\section{Acknowledgments}

This work was financed by Scientific Grant Agency of Ministry of Education of Slovak Republic and Slovak Academy of Science - projects VEGA 1/0301/20, VEGA $1 / 0143 / 20$ and KEGA 002TUKE-4/2019. This work was also supported by the Development Operational Programme Research and Innovation for the project" New unconventional magnetic materials for applications", ITMS: 313011T544, co-funded by the European Regional Development Fund (ERDF).

\section{References}

[1] B. Glaubbitz, S. Buschhorn, F. Brussing, R. Abrudan, H. Zabel, J. Phys. Condens. Matter 23, 25 (2011).

[2] B.P. Weiss, J. Gattaccera, S. Stanley, P. Rochette, U.R. Christensen, Space Sci. Rev. 152, 1 (2010).

[3] M.W.R. Volk, M.R. Wack, B.J. Maier, J. Alloys Compd. 732, 336 (2018).

[4] Y. Geng, T. Ablekim, M. A. Koten, M. Weber, K. Lynn, J.E. Shield, J. Alloys Compd. 633, 250 (2015).

[5] J. Zhou, W. Yang, Ch. Yuan, B. Sun, B. Shen, J. Alloys Compd. 742, 318 (2018).

[6] D. Olekšáková, P. Kollár, J. Füzer, Acta Phys. Pol. A 133, 639 (2018).

[7] M. Karolus, E. Jartych, D. Oleszak, Acta Phys. Pol. A 102, 253 (2002).

[8] C. Suryanarayana, Prog. Mater. Sci. 46, 1 (2001).

[9] P. Kollár, P. Slovenský, D. Olekšáková, M. Jakubčin, Z. Birčáková, J. Füzer, R. Bureš, M. Fáberová, J. Magn. Magn. Mater. 494, 165770 (2020).

[10] W. Steinhaus, E. Gumlich, Verhandl. Deut. Physik. Ges 17, 369 (1915).

[11] M. Nowicki, Materials 11(10), 1 (2018).

[12] J. Pearson, P.T. Squire, D. Atkinson, IEEE Trans. Magn. 33, 3970 (1997).

[13] P. Kollár, Z. Birčáková, V. Vojtek, J. Füzer, R. Bureš, M. Fáberová, J. Magn. Magn. Mater. 388, 76 (2015).

[14] L. Novák, A. Lovaš, L.F. Kiss, J. Appl. Phys. 98, 043904 (2005).

[15] D.C. Jiles, D.L. Atherton, J. Magn. Magn. Mater. 61, 48 (1986).

[16] N.C. Pop, O.F. Calton, Acta Phys. Pol. A 120, 491 (2011).

[17] B. Kvasnica, F. Kundracík, J. Magn. Magn. Mater. 162, 43 (1996).

[18] Z. Birčáková, P. Kollár, J. Füzer, R. Bureš, M. Fáberová, J. Magn. Magn. Mater. 502, 166514 (2020). 